\section{É possível confiar nas pesquisas eleitorais? Análise das intenções de votos nas eleições para governadores no Brasil em 2014}

\author{
[Is it possible to rely on polls? \\ Analysis of the intentions of \\ votes in the elections for \\ governors in Brazil in 2014]
}

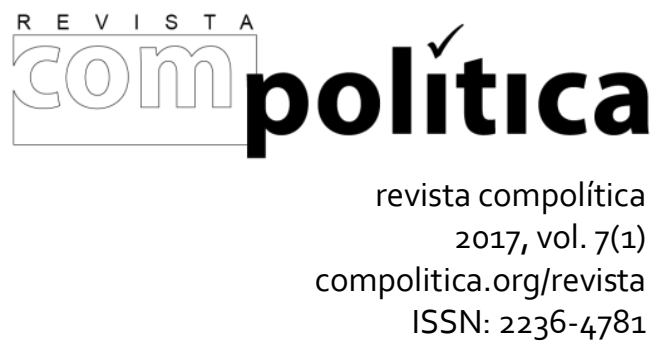

DOI: 10.21878/compolitica.2017.7.1.224 () Open Access Journal

\author{
João Kamradt \\ Universidade Federal de Santa Catarina \\ [Federal University of Santa Catarina]
}

\begin{abstract}
Resumo
Pesquisas de opinião sobre candidatos a cargos públicos são muito utilizadas em época de eleição. Os dados servem para mostrar qual é a fotografia do momento, quem está na frente e apontar tendências de queda ou crescimento para os pesquisados. E aí reside um problema. Mesmo com tanta importância, são escassos os estudos que medem o grau de confiabilidade das pesquisas eleitorais no Brasil. É disto que este artigo trata. Após fazer uma breve revisão da literatura sobre as pesquisas eleitorais e a opinião pública, o trabalho apresenta um balanço feito com 77 pesquisas de 23 institutos diferentes nos 27 estados brasileiros antes da realização do primeiro e do segundo turno das eleições de 2014 no Brasil. Ao todo, foram analisados 302 candidatos. Os resultados indicaram que 32\% dos candidatos pesquisados tiveram previsões que não se realizaram, sendo que a maioria dos erros se deu no primeiro turno. Quase $15 \%$ das pesquisas apresentaram candidatos trocando de posições entre a previsão e o resultado nas urnas. Entre as razões para tantos equívocos estão a utilização da margem de erro, a coleta de dados feita em um período distante do pleito e a quantidade de eleitores indecisos até a proximidade da votação. Palavras-chave: opinião pública; pesquisas eleitorais; confiabilidade das pesquisas; eleições 2014; Brasil.
\end{abstract}

\begin{abstract}
Opinion polls on candidates for public offices are widely used at election time. The data are used to show which is the picture of the moment, which candidates are in the lead and pointing downward trends or growth for the respondents. And therein lies a problem. Even with such importance, there are few studies that measure the degree of reliability of polls in Brazil. This is what this article is about. After making a brief review of the literature on polls and public opinion, the work presents a debriefing with 77 research institutes in 23 different 27 states prior to the first and second round of the 2014 elections in Brazil. In all, 302 candidates were analyzed. The results indicated that $32 \%$ of the candidates surveyed had forecast that did not occur, and that most errors occurred in the first round. Almost $15 \%$ of the research presented candidates swapping positions between the forecast and the result at the polls. Among the reasons for so many misconceptions are using the margin of error, data collection made in a distant period of the election and the number of undecided voters to the closeness of the vote.
\end{abstract}

Keywords: public opinion; polls; reliability of research; elections 2014; Brazil. 


\section{É possível confiar nas pesquisas eleitorais? Análise das intenções de votos nas eleições para governadores no Brasil em 2014}

opinião pública tem papel ratificador na condução política e cultural. No
século XX, o crescimento e aprimoramento das empresas de mídia elevaram a
sua importância, com as pesquisas eleitorais sendo um dos principais exemplos. Pesquisas são contratadas e divulgadas pela mídia para medir o percentual de adesão que um candidato possui nos períodos que antecedem a votação. Mas, se as medições são fundamentais para o jogo político, elas devem isso à importância atribuída à opinião pública ao longo do século passado. Devido à falta de clareza e às inúmeras definições atribuídas ao conceito, começarei esse artigo com uma breve revisão da literatura sobre o tema. Posteriormente, farei uma revisão sobre a história e a conceituação das pesquisas eleitorais no Brasil.

Em seguida, serão apresentados dados de um levantamento para checar a quantidade de acertos e erros dos números medidos pelos institutos nas pesquisas eleitorais realizadas no Brasil para o cargo de governador em 2014. Foram coletadas 77 medições dos 27 estados brasileiros. Todas as pesquisas examinadas foram as últimas conduzidas pelos institutos antes do pleito, tanto no primeiro como no segundo turno, sempre de acordo com o Tribunal Superior Eleitoral (TSE). Foram analisadas 23 diferentes empresas responsáveis pelas pesquisas, somando um total de 290 candidatos averiguados. Os resultados surpreendem: ao contrário do que atestam os institutos, 93 candidatos ou $32 \%$ dos nomes tiveram previsões que não se realizaram levando em conta a margem de erro estipulada. A maioria dos erros se deu no primeiro turno das eleições. Quase $15 \%$ das pesquisas trouxeram candidatos trocando de posições entre a medição e o resultado das urnas. Nas duas últimas seções, são apontadas razões para os erros das pesquisas, levando em conta fatores exógenos a elas. 


\section{A opinião pública em debate}

Uma das concepções mais comuns de opinião pública é a que a define como soma de opiniões ou aquilo que as sondagens de intenção de votos expressam. Essa é uma visão redutora do conceito que tem facetas cujas concepções se dividem em duas correntes principais. Uma delas alega que a opinião pública não representa a verdade. Por ser público, o termo pertenceria ao universo político. Logo, o correto seria falar sobre opiniões públicas. Na busca por entendimento histórico, podemos alegar que a opinião pública surge paralelamente à formação do Estado moderno quando ocorre a separação entre sociedade civil e Estado. Habermas (1984) enxerga a esfera pública burguesa e iluminista como um local de comunicação. Ali, a opinião pública aparece na discussão entre atores que utilizam argumentos racionais. O espaço público é uma esfera de discussão, um local de mediação entre a sociedade civil e a sociedade política. $\mathrm{O}$ autor enxerga a importância da imprensa no funcionamento dessa esfera, já que é um "instrumento com cuja ajuda decisões políticas podem ser tomadas perante o novo fórum do público" (Habermas, 1984, p.76).

Outra abordagem muito citada é de Arendt (1972). Ela vê a "cena pública" associada ao conceito de "visibilidade". Aqui, há um processo de publicidade que acontece independentemente da existência de justificativas racionais. A opinião pública seria composta de "juízos reflexivos", não precisando ser racionais para quem observa a cena pública, formando um "sentido comum" para entender os acontecimentos e atores da ação. Para Arendt, a opinião pública pertence à ordem da persuasão. Para Habermas, é o argumento racional que surge como modelo normativo.

No liberalismo, uma das noções mais conhecidas é a de Tocqueville (1981). Ele argumenta que uma sociedade orientada pela opinião pública veria a maioria prevalecer e isso faria as minorias desaparecerem. Além disso, a preferência da maioria geraria empobrecimento do espírito crítico da população, coerção para quem segue a mesma opinião da massa, conformação com a opinião vigente e intolerância com as minorias. Tocqueville enxergava na opinião pública a materialização do princípio de soberania popular. Para o autor, uma opinião “que já não persuade com as suas convicções, apenas 
as impõe e fá-las penetrar nos espíritos através de uma espécie de imensa pressão exercida sobre a inteligência de cada um" (Tocqueville, 1981, p.17-18).

Locke (2002) define a questão por meio da correlação que o termo possui com a soberania popular, a moral, as leis e os costumes. Para o autor, ao formar uma sociedade política, os homens abdicaram do poder individual em prol do poder político no qual é possível usar a força contra os concidadãos. Enquanto isso, mantiveram o poder de julgar o vício, a virtude, a bondade e a maldade das ações. Na estruturação do Estado liberal, há uma distinção radical entre a lei civil, manifestada pela assembleia representativa, e a lei moral, expressa pela opinião pública (Locke, 2002). A opinião pública seria um intermediário entre o eleitorado e o poder legislativo ou executivo. Teria a função de permitir que todos os cidadãos participassem, dando condições para que se manifestassem e discutissem suas opiniões sobre assuntos de interesse geral.

Olhando do ponto de vista político, a opinião pública surge como a voz do povo, sendo responsável pela ponte entre quem governa e os governados. A opinião pública seria uma legitimação política da qual surge o poder do consentimento dos governados aos governantes. O problema na definição do que é a opinião pública ocorre devido ao fato de que a popularização da expressão criou uma amplitude que tornou qualquer definição limitada ou muito rígida.

Entre as críticas ao conceito de opinião pública, uma das mais conhecidas vem de Bourdieu (1982). Ele afirma que a noção de opinião pública defendida pelos institutos de pesquisa não é verdadeira. A crítica é de que existem problemas na forma de captação da opinião pública por parte dos institutos que impossibilitam a apreensão legítima da opinião pública. Esses problemas se apresentariam tanto na formulação das perguntas quanto na maneira como são obtidas as opiniões dos indivíduos. Os problemas apontados possuem, como base, três argumentos. Segundo Bourdieu, os pesquisadores impõem temas que não seriam de interesse de quem os responde. Temas importantes aos pesquisadores não seriam os mesmos dos entrevistados. Outro argumento é de que os responsáveis pela pesquisa partem da premissa, rejeitada por Bourdieu, de que a construção da opinião está ao alcance de todo indivíduo. Ele também questiona o fato de 
que os pesquisadores acreditam que as opiniões de todas as pessoas possuem valor idêntico.

(...) o que me parece importante é que a pesquisa de opinião trata a opinião pública como uma simples soma de opiniões individuais que seriam recolhidas numa situação que é, no fundo, a da cabine eleitoral, onde o indivíduo vai furtivamente. Esta concepção da opinião pública ignora que as relações entre opiniões são conflitos de força. Tomar posição sobre tal ou qual problema é escolher entre grupos reais e, simultaneamente, o terceiro postulado, ou seja, que todas as opiniões se equivalem, é totalmente desprovido de fundamento (Bourdieu, 1982, p. 147)

Bourdieu considera que existe uma "defasagem considerável" entre a opinião das pessoas em uma entrevista, considerada uma situação artificial, e aquela pelas quais os entrevistados produzem numa situação próxima do que vivem. Para Bourdieu, a função da sondagem é construir uma ilusão de que há uma única opinião pública, como se fosse possível somar todas as opiniões dadas individualmente e se pudesse representá-la por meio de um percentual. É na expressão de uma opinião pública única que o jornalismo entra no debate. Jornalismo e política estão ligados as pesquisas de opinião desde suas origens. Em um registro histórico impreciso, surgem com as straw polls, enquetes feitas por jornalistas a partir de 1820, que não possuíam critério técnico ou estatístico.

Essa modalidade de pesquisa se manteve em alta por décadas até que a revista Literary Digest errou por muito o resultado da campanha presidencial americana de 1936. O erro aconteceu ao mesmo tempo em que pesquisas com melhores metodologias, conduzidas por George Gallup, começaram a acertar o resultado. Isso serviu como transição entre dois modos distintos de medir a opinião pública (Herbst, 1993). Gallup utilizava a amostragem por cotas, entrevistas feitas pessoalmente para eliminar o efeito tendencioso das respostas voluntárias nas straw polls. Ele previu a reeleição de Roosevelt com 55,7\% dos votos. Errou por $6,8 \%$, mas acertou o vencedor.

A consolidação das pesquisas por método da amostragem ocorreu, mas encontrou doses de ceticismo. Vigorava entre políticos a noção de que os jornais e revistas não captavam o sentimento popular (Herbst, 1993, p.102). As ideias de Lippmann, de que sujeitos com 
pouco interesse em política e limitações para compreender as questões perguntadas também afetavam a qualidade das pesquisas, tinham grande aceitação. Para Lippmann, "os clichês dentro das cabeças de seres humanos, os clichês deles próprios, de outros, de suas necessidades, propósitos e afinidades são suas opiniões públicas” (2008, p.29).

Mas, com o tempo e os acertos, as pesquisas de opinião acabaram tendo como principais consumidores os grupos de mídia. É assim que Champagne coloca as sondagens como canais importantes em uma democracia, já que "presume-se que, tradicionalmente, o povo se exprime e chega a pensar, de forma mais ou menos direta, sobre o jogo político" (2005, p.382). Para o autor, quando cientistas políticos começaram a reunir amostras representativas da totalidade das pessoas com idade mínima para votar, pontos sensíveis do regime democrático passaram a ser afetados. A base científica proposta pelas pesquisas, que espelhavam a própria lógica democrática, fez com que as medições de voto não fossem confrontadas pelos políticos:

(...) ao realizar (...) referendos que pretendem medir, de maneira precisa e indiscutível, a "opinião pública", ou seja, a "vontade popular", e ao fazer votar, de maneira permanente, amostras de população que, supostamente, representam o corpo eleitoral, os profissionais das sondagens contribuíram para enfraquecer o poder próprio dos eleitos, ao modificarem a lógica representativa que governava o estado antigo do regime democrático (Champagne, 2005, p. 383-384).

Para Manin (1995), os meios de comunicação legitimam às pesquisas de opinião. Ele acredita que as medições são responsáveis por refletir com alto grau de precisão um eleitorado instável, menos vinculado a partidos e com preferências menos reguladas por condições socioeconômicas. Manin alega que as pesquisas criam uma forma peculiar de "manifestação não-eleitoral da vontade popular". Isso aconteceria porque os custos para a expressão individual das posições políticas ficariam mais baratas.

Em relevante trabalho, Bishin (2009) analisa como diversas decisões legislativas na política norte-americana são tomadas na contramão das pesquisas de opinião, que demostram a maioria do eleitorado pendente para um lado enquanto a decisão tomada vai 
para o outro. Para o autor, esses resultados seriam atribuídos ao peso maior que pequenos grupos altamente mobilizados conseguem ter em torno de questões específicas. Temas que causam divisões entre republicanos e democratas ou que recebem lobby de atores altamente comprometidos com suas posições acabam entrando no Legislativo e alterando o seu status quo legal. O autor usa o embargo que existia por parte dos EUA contra Cuba como um exemplo. No caso, mesmo com a maioria da população não se opondo ao livre comércio entre os países, uma minoria localizada em Miami conseguia fazer valer sua posição contrária ao acordo. Mas, o trabalho de Bishin se refere a decisões legislativas em que um grupo mobilizado consegue reverter tendências majoritárias. O mesmo, por hora, não pode ser aplicado para eleições.

\section{A influência e a importância das pesquisas nos processos eleitorais}

Em todo mundo, pesquisas eleitorais são fontes independentes que indicam a preferência da população por um candidato. As pesquisas são um recurso simbólico e importante das disputas por agentes sociais, potencializando a legitimação de discursos e de tomadas de posição no espaço público, assim como indicando a popularidade dos políticos. Também são utilizadas para accountability dos representantes eleitos e como checagem contínua sobre a posição dos candidatos dentro de uma disputa.

Em campanhas, as pesquisas se tornaram fundamentais. As medições cresceram no mesmo ritmo em que os consultores políticos especializados em marketing eleitoral ganharam espaço na tomada de decisões dos candidatos. Para Amaral (2000), os partidos usam as pesquisas de opinião para montar o processo de construção das candidaturas, monitorando a vontade da maior parte dos integrantes da sigla. Também funcionariam como instrumento para adequar o perfil ideal do político projetado pela população, procedimento essencial ao "exercício da função de controle da imagem política por parte dos atores políticos" (Gomes, 2004, p.289). Assim, se constrói a opinião pública favorável. Para a mídia, a pesquisa eleitoral virou rotina, sendo agendada como mais uma notícia a ser dada na cobertura de uma campanha eleitoral. 
Nas empresas midiáticas, as pesquisas eleitorais se tornaram uma ferramenta importante, revelando a "fotografia do momento". A presença constante nos meses e dias que antecedem as eleições é justificada pela necessidade de informar aos eleitores sobre as chances dos candidatos e suas perspectivas futuras. No Brasil, foi a partir da década de 1980, junto com a redemocratização do país, que as parcerias comerciais entre os institutos de pesquisa e os veículos de comunicação ganharam evidência. Os institutos mostravam a projeção da disputa pelos cargos públicos e tinham sua veracidade validada pela imprensa, que projetava credibilidade nas operações de divulgação das pesquisas pré-eleitorais. Essa interação comercial de divulgação e promoção dos institutos de pesquisas e dos meios impressos é saudada por teóricos.

A pesquisa de opinião pública (...) tornou o mais importante elemento da democracia, a vontade do povo, mensurável, e, assim, disponível para o processo decisório quase diariamente. Essa revolução afetou a própria natureza do sistema político em seu cerne, pois possibilitou que se avaliasse de maneira direta alegações de agir com o consentimento da maioria das pessoas (Donsbach; Traugott, 2008, p.3)

Poder medir aspirações e opiniões de partes significativas do povo daria algo palpável à noção pouco concreta de opinião pública e ao princípio de soberania popular. Implicitamente, as pesquisas passaram a dizer para os cidadãos que não era necessário esperar até as eleições para confrontar os políticos eleitos. Isso, para os autores, daria um efeito "revolucionário" para as medições. Já Noelle-Neumann faz uma crítica às pesquisas por meio do conceito de "espiral do silêncio" (1993). Observando as eleições nacionais na Alemanha em 1965, ela desenvolveu uma teoria sobre o bandwagon effect ${ }^{1}$, um modo de resposta típico dos indivíduos ao clima da opinião que cada um possui sobre qual é a opinião majoritária no momento. Com esse pressuposto, o ser humano se posicionaria publicamente de forma a evitar o isolamento social, checando as opiniões que ganham ou perdem força no contexto em que está inserido. O silêncio se constitui como uma das respostas utilizadas por esses indivíduos, cujas opiniões seriam

\footnotetext{
${ }^{1}$ Bandwagon effect é o termo empregado para indicar a tendência do eleitor em dar seu voto ao candidato que aparece como favorito. Já o conceito underdog se refere ao candidato mais fraco.
} 
minoritárias. Isso levaria a uma percepção de que uma opinião majoritária se ampliasse ainda mais (frente ao silêncio dos com opinião minoritária) em um processo de forma espiral. Noelle-Neumann busca enfatizar que esse tipo de comportamento era típico de uma sociedade com uma opinião coletiva formada, que agiria como um dispositivo de controle social e de pressão sobre os sujeitos. A forma de escapar disso, segundo a autora, é que as noções de opinião pública se formem por um público politicamente ativo e informado que não leve em conta o comportamento de terceiros.

\section{Como são feitas as pesquisas eleitorais no Brasil}

No Brasil, para serem publicadas, as pesquisas precisam cumprir obrigações legais, que servem para fiscalizar os institutos. Quem faz e divulga ${ }^{2}$ pesquisas eleitorais no Brasil precisa de um registro junto à justiça eleitoral até cinco dias antes da divulgação do resultado. Também são entregues à justiça os dados do contratante da pesquisa, o valor pago, a metodologia utilizada, o período de coleta dos dados, o plano amostral e a ponderação. Os institutos brasileiros utilizam a amostragem por cotas. Isso mostra a quantidade de pessoas de cada sexo, idade, grau de instrução, nível econômico e a área física em que se realizam as entrevistas. Informações como o intervalo de confiança e margem de erro também são cedidas. Além disso, é necessário fornecer o questionário completo e dar acesso à justiça ao sistema interno de controle de verificação, conferência e fiscalização da coleta de dados e do trabalho de campo (TRE-SE, 2014) ${ }^{3}$.

As pesquisas utilizam as informações cedidas pelo Instituto Brasileiro de Geografia e Estatística (IBGE) para conhecer o perfil do eleitor em cada estado e cidade. De acordo com o tamanho da população, da quantidade de mulheres e homens, dos empregos e da escolaridade dos indivíduos, o instituto divide a amostra de forma que cada cidade represente um espelho do Estado. Concluído esse processo, o questionário é preparado e

\footnotetext{
${ }^{2}$ Quem não vai divulgar as pesquisas, pode fazer como achar melhor sem seguir padrões rígidos de conduta. Um exemplo são as ligações telefônicas efetuadas para uma região depois da propaganda eleitoral. A track não segue nenhum critério, a não ser o fato de as pessoas morarem em uma mesma região.

${ }_{3}^{3}$ Pesquisas que não cumpram estes requisitos são multadas em valores que variam de R\$ 53 mil a R\$ 106,4 mil.
} 
as entrevistas são feitas, em geral, de dois a seis dias. As entrevistas são realizadas por técnicos que vão de casa em casa ou por agentes nas ruas.

Outro fato que contribuiu na melhora das pesquisas é o georreferenciamento computadorizado $^{4}$ utilizado pelos institutos desde 2005. Segundo João Francisco Meira, diretor do Instituto Vox Populli, o processo melhorou a amostragem coletada da população, permitindo avanços estatísticos e maior precisão. Além disso, técnicas como a ciência do comportamento e psicologia experimental foram incorporadas no processo de estruturação das pesquisas e de obtenção dos dados. Isso, segundo Meira, faz com que "uma amostra relativamente pequena consiga ter um grau de precisão muito grande" (Meira, 2010, p.21). Mas, se há melhora no processo de realização das pesquisas, por que as pesquisas não correspondem à realidade?

\section{As pesquisas para governador no Brasil: acertos e erros}

Pesquisas eleitorais divulgam uma margem de erro que não costuma ultrapassar os três pontos percentuais para cima ou para baixo. Essas medições apresentam índice de confiança médio de $95 \%$. Ou seja, de cada 100 pesquisas de opinião divulgadas, apenas cinco deveriam ultrapassar a margem de erro prevista. É esse o grau de confiabilidade que os institutos afirmam para as medições. Mas o Brasil carece de estudos quantitativos que demonstrem se existe uma relação de confiabilidade entre o que os institutos divulgam e o resultado. Artigos de pesquisadores brasileiros fizeram comparações entre pesquisas, mas tratavam sobre pesquisas realizadas em um único pleito (Oliveira, 2010; Cervi, 2009). Aqui são abordadas as eleições de 2014 para governador em todos os estados brasileiros.

Em cada estado, foram coletadas as últimas duas pesquisas feitas por diferentes institutos e divulgadas em um órgão da mídia antes das eleições. Nos estados com segundo turno, foram coletadas outras duas pesquisas, novamente em institutos diferentes, nos dias que

\footnotetext{
${ }^{4}$ Georreferenciamento é um sistema obrigatório no Brasil que permite avaliar com maior grau de precisão propriedades rurais e estradas que antes não eram computadas demograficamente.
} 
antecederam o pleito. Com isso, foram coletadas e analisadas 77 pesquisas de 23 institutos diferentes. O Ibope, por ser o único instituto a fazer pesquisas em todos os estados, tem o maior número de pesquisas analisadas, seguido pelo DataFolha. Os critérios para a seleção das medições foram: as pesquisas estarem registradas na justiça e ter suas entrevistas realizadas o mais próximo possível da votação. Esse último requisito tenta criar uma análise comparativa entre o resultado medido naquele período e os votos obtidos pelos candidatos. Para fazer uma comparação entre o percentual que cada instituto atribuiu a um candidato e aquilo que obteve nas urnas, foram utilizados nas comparações apenas os votos válidos. Os eleitores entrevistados indecisos não entraram na conta. Os que votariam em branco ou nulo também foram excluídos. Esse método serviu para criar um parâmetro que torne possível uma comparação entre as pesquisas e o resultado das urnas. Mesmo assim, sabe-se que nos momentos finais da campanha, os candidatos fazem campanha para os indecisos. Mas, considerando que as pesquisas apontam tendências, a suposição dos institutos é que os percentuais indiquem o resultado final, considerando os indecisos.

Foram reunidos os dados das eleições para governador de todos os estados, no primeiro e segundo turno ${ }^{5}$. Após isso, foram conferidos os resultados de cada um dos 302 candidatos pesquisados (os nomes se repetem) nas pesquisas e no resultado final, utilizando como parâmetro o total de votos válidos pelas pesquisas (quando não apresentados, os dados foram calculados pelo autor). O objetivo era checar:

a) Os institutos acertam as posições dos candidatos após a conclusão da apuração dos votos?

b) As pesquisas cumprem a margem de erro que estabelecem?

c) Os institutos possuem uma média de acertos distinta entre o $1^{\circ}$ e o $2^{\circ}$ turno?

d) Quando (e se) erram, as pesquisas apresentam erros em mais de um candidato?

\footnotetext{
${ }^{5}$ Em alguns estados, os veículos que disponibilizaram a pesquisa o fizeram de modo que fica inviável se calcular o número de votos válidos, o que impossibilita a comparação. Assim, estados que possuem apenas uma pesquisa utilizada nesse trabalho são: Amapá, Roraima, Rondônia e Tocantins, referentes a pesquisas do primeiro turno; e Rio Grande do Norte, em pesquisa para o segundo turno.
} 
Antes de tratar dos dados, é necessário lembrar que a margem de erro tem uso controverso. Nos EUA, pesquisas quantitativas feitas por amostragem por cotas não utilizam margem de erro. Como afirmam Carvalho e Ferraz (2006), citando o estudo de Leslie Kitsch, o método de amostragem para pesquisas não é científico. A alegação é de que, embora supostamente consiga ter um bom grau de precisão, não haveria explicação científica para esperar por esse acerto. Isso porque as pesquisas não se baseiam em nenhuma probabilidade conhecida de seleção. No estudo de inferência estatística, as amostras de cotas não seriam usadas por não corresponder aos pressupostos teóricos associados à técnica. A explicação para o uso nas pesquisas brasileiras é de que são mais baratas. Estabelecer margem de erro é um contrassenso: "nós achamos que a declaração da margem de erro em amostragem por cotas configura-se em um erro estatístico, aqui usando-se o termo como empregado em erro médico" (Carvalho; Ferraz, 2006, p.4). O correto, segundo eles, seria utilizar a amostragem aleatória. Essa é mais cara, mas traz resultados mais precisos. Outra solução seria excluir a margem de erro da pesquisa que utiliza amostra por cotas.

Por esse motivo, as margens de erros precisam ser colocadas à prova. Tanto os institutos como as empresas de mídia que divulgam as pesquisas se valem dos percentuais apresentados pelas medições e da margem de erro como garantia de confiabilidade. $\mathrm{Na}$ página seguinte apresento um diagrama com alguns dos dados obtidos.

Mais de quatro quintos das pesquisas realizadas no primeiro turno, $82,3 \%$, apresentaram ao menos um candidato fora da margem de erro. Enquanto isso, das 26 pesquisas analisadas para o segundo turno, apenas seis estiveram fora da margem de erro. Isso representa $23 \%$ de erros. Percentual acima do prometido pelos institutos, mas menor do que o apresentado nas pesquisas de primeiro turno. Uma conclusão que se chega é a de que pesquisas feitas em eleições com menor número de candidatos possuem maior precisão. Quando há mais nomes, há dificuldade em medir a opinião pública com exatidão, mesmo utilizando a margem de erro. Isso fica evidente ao se notar que dos seis erros dos institutos, quatro foram no Mato Grosso do Sul, ao errar os percentuais de Delcídio Amaral (PT) e de Reinaldo Azambuja (PSDB). 
Diagrama 1: Acertos e erros das pesquisas

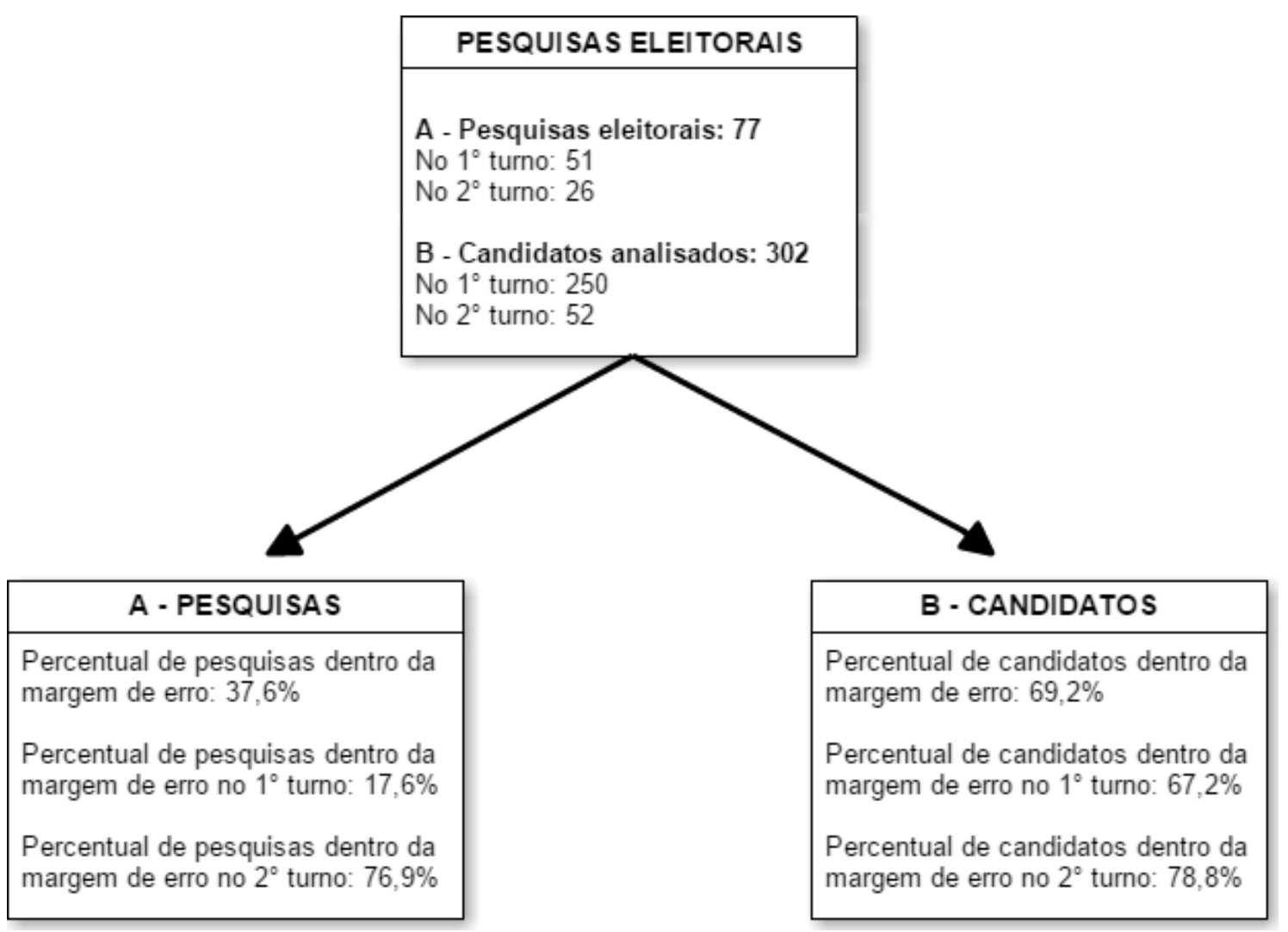

Fonte: Elaboração do autor.

Ao se analisar quantos candidatos as pesquisas mantiveram dentro da margem de erro, os números se alteram para baixo. Considerando os 302 nomes de candidatos avaliados (lembrando que há nomes repetidos), 93 estiveram fora da margem de erro. Isso representa $30,7 \%$ de erros. Separado por turnos, os erros são em número mais elevado no primeiro do que no segundo. Enquanto no primeiro turno foram 82 erros entre 250 nomes pesquisados, que totalizaram $32,8 \%$ da amostra analisada, entre os 52 nomes medidos no segundo turno, houve 11 erros, o que significa $21,1 \%$.

Agora, especifico questões que mostram até que ponto os institutos e a mídia (esta por comprar e publicar as pesquisas) entregam o que prometem: um panorama do que está ocorrendo e uma previsão balizada pela margem de erro para as eleições. A seguir, 
apresento dados sobre pesquisas que tiveram um, dois ou mais nomes de candidatos fora da margem de erro.

Diagrama 2: Candidatos fora da margem de erro

\begin{tabular}{|l|}
\hline \multicolumn{1}{|c|}{$\begin{array}{c}\text { Um candidato fora da } \\
\text { margem de erro }\end{array}$} \\
\hline Total de pesquisas: $77(100 \%)$ \\
Em pesquisas no $1^{\circ}$ turno: $11(14,3 \%)$ \\
Em pesquisas no $2^{\circ}$ turno: $1(1,3 \%)$ \\
Total de candidatos: $302(100 \%)$ \\
Total de erros: $12(4 \%)$ \\
\end{tabular}

\begin{tabular}{|l|}
\hline $\begin{array}{c}\text { Dois candidatos fora da } \\
\text { margem de erro }\end{array}$ \\
\hline Total de pesquisas: $77(100 \%)$ \\
Em pesquisas no $1^{\circ}$ turno: $11(14,3 \%)$ \\
Em pesquisas no $2^{\circ}$ turno: $1(1,3 \%)$ \\
Total de candidatos: $302(100 \%)$ \\
Total de erros: $54(17,9 \%)$ \\
\end{tabular}

\begin{tabular}{|l|}
\hline \multicolumn{1}{|c|}{$\begin{array}{c}\text { Três candidatos fora da } \\
\text { margem de erro }\end{array}$} \\
\hline Total de pesquisas: $51(100 \%)^{*}$ \\
Em pesquisas no $1^{\circ}$ turno: $9(17,6 \%)$ \\
Total de candidatos: $250(100 \%)$ \\
Total de erros: $27(10,8 \%)$ \\
* Só leva em conta as pesquisas do \\
$1^{\circ}$ turno.
\end{tabular}

Fonte: Elaboração do autor.

Ampliar a análise sobre a quantidade de erros dos nomes de candidatos ajuda a compreender que os equívocos das pesquisas não são solitários. Das 77 pesquisas observadas, apenas 29 não possuíam equívoco na relação entre o percentual estipulado aos candidatos e o obtido nas urnas. Ou seja, 37,6\%. Dos 44 que cometeram equívocos, apenas 12 tiveram um único nome fora da margem de erro. Logo, 36 medições ou 53,2\% do total trouxeram ao menos dois nomes que ficaram fora da margem de erro. Um exemplo é a pesquisa Ibope para governador na Bahia. A pesquisa apontava os 
candidatos Paulo Souto (DEM) e Rui Costa (PT) com 46,1\% dos votos válidos. Mas as urnas mostraram Rui Costa obtendo 54,5\% contra 37,3\% de Paulo Souto. Pode se afirmar que o número de candidatos em uma disputa impede que os institutos estabeleçam com maior precisão os percentuais que cada um obterá. Mesmo com erros, existe diferença entre os percentuais levemente acima da margem de erro proposta e as pesquisas que erram a posição dos candidatos e cometem erros superiores a 10\%. Mesmo sendo um número menor do que os apresentados acima, ainda é superior aos $95 \%$ de índice de confiança que os institutos atribuem às pesquisas.

Agora, mostro quantas pesquisas apresentaram erros percentuais superior aos $10 \%$ e quantas erraram a posição dos nomes pesquisados.

\section{Diagrama 3: Erros na posição dos candidatos}

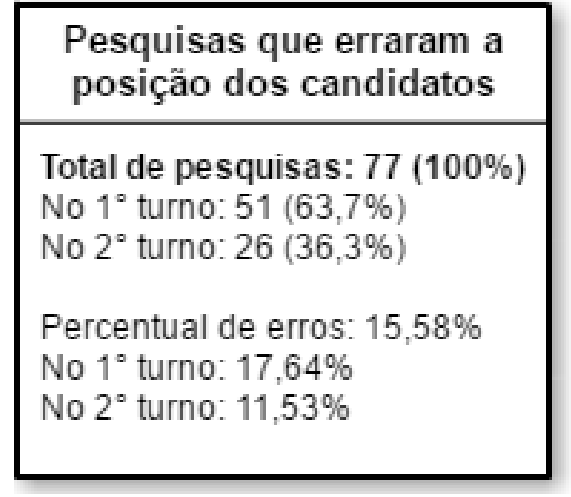

Fonte: Elaboração do autor.

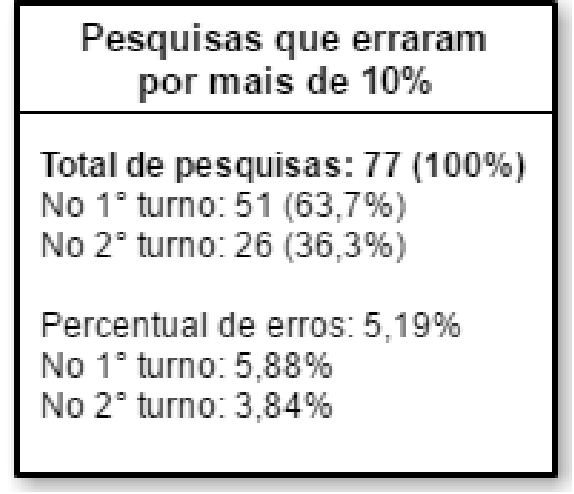

Duas percepções ficam evidentes: as pesquisas não erram por grandes diferenças no segundo turno, salvo exceções ${ }^{6}$, e são mais confiáveis para indicar qual o candidato que terminaria a eleição na frente no segundo turno. É possível concluir que mesmo com erros apresentados, os institutos apontam na direção certa, ainda mais no segundo turno. Das pesquisas analisadas, em 15,5\% houve troca de posição dos candidatos. Nenhuma

\footnotetext{
${ }^{6}$ Em 2012, em pesquisa fora do escopo de análise deste artigo, o Ibope fez uma medição sobre a disputa pela prefeitura de Joinville (SC). Os índices apontavam vitória de Kennedy Nunes (PSD) sobre Udo Döhler (PMDB): $59 \%$ contra $41 \%$. O resultado foi quase o oposto. Döhler venceu Kennedy por $54,65 \%$ a $45,35 \%$. As justificativas para o caso foram a velocidade de acesso que os eleitores possuem às informações hoje facilitam mudanças em "cima da hora".
} 
das trocas ocorreu no segundo turno. Enquanto isso, 5,1\% das pesquisas apresentaram ao menos um candidato com erro superior a $10 \%$ quando comparado com o resultado. Entre os casos estão o da pesquisa Fiems/Ibrape no Mato Grosso do Sul. Lá, não houve mudança de posição, mas uma diferença entre o percentual divulgado e a votação obtida por Delcídio do Amaral (PT) e Reinaldo Azambuja (PSDB) A pesquisa, realizada entre $1^{\circ}$ e 03 de outubro, entrevistou 1.012 pessoas e teve margem de erro de 3\%. Amaral aparecia em primeiro lugar com 51\% e Azambuja com 28\%. Mas, nas urnas, Amaral teve 42\% enquanto Azambuja 39\% dos votos válidos.

Agora, darei atenção ao Ibope. Por ser o instituto mais utilizado no país e o único a realizar pesquisas em todos os estados, ele foi o mais analisado. Foram 41 pesquisas, o que representa mais da metade dos dados levantados. A análise dos dados do instituto revela o seguinte:

Diagrama 4: Pesquisas do lbope

\begin{tabular}{l} 
CANDIDATOS ANALISADOS PELO IBOPE \\
\hline Quantidade de candidatos: 163 \\
Percentual total dentro da margem \\
de erro: $73,01 \%$ \\
Percentual total fora da margem \\
de erro: $26,99 \%$ \\
Primeiro turno: 135 \\
Percentual de candidatos dentro da \\
margem de erro: $27,41 \%$ \\
Percentual de candidatos fora da \\
margem de erro: $72,59 \%$ \\
Segundo turno: 28 \\
Percentual de candidatos dentro da \\
margem de erro: $75 \%$ \\
Percentual de candidatos fora da \\
margem de erro: $25 \%$
\end{tabular}

Fonte: Elaboração do autor. 
Pode ser observado o alto número de erros que as pesquisas apresentaram no primeiro turno, mostrando a dificuldade que as medições possuem em interpretar cenários com mais de dois candidatos. Dos 135 candidatos analisados durante o primeiro turno, $72,5 \%$ estavam fora da margem de erro estabelecida. É um percentual distante da margem de erro estipulada. Enquanto isso, no segundo turno, o percentual é consideravelmente mais baixo, ficando em $25 \%$. Isso indica a dificuldade que os institutos de pesquisa possuem com cenários de múltiplas escolhas.

Agora, podemos responder as perguntas do começo desta sessão. Sobre a questão se as pesquisas realizadas pelos institutos acertam a posição dos candidatos: acertam uma média de 88 vezes a cada 100 pesquisas. O resultado não corresponde ao prometido. Mas problema maior é a resposta para a questão que busca constatar se as pesquisas respeitam a margem de erro estabelecida. A resposta é que há um erro a cada duas análises, ou seja, distante do padrão estabelecido e longe da confiabilidade autoproclamada dos institutos e outorgada pelos meios de comunicação quando as publicam. O equívoco da margem de erro indica, em tom otimista, que as pesquisas conseguem, no máximo, indicar tendências. Cenário que muda ao se responder a terceira pergunta, que é ver se a média de acertos entre o primeiro e o segundo turno eram semelhantes ou distintas. Aí fica claro que, em um cenário consolidado, com dois candidatos em campanha há meses, as pesquisas alcançam maior confiabilidade, mas ainda fora da margem prometida. Se no primeiro turno não há confiabilidade, no segundo, a relação é de mais de um erro a cada quatro casos. Por fim, a resposta para a quarta pergunta também não mostra um cenário otimista para as pesquisas. O questionamento visava descobrir se os erros eram isolados. A resposta é que quando as pesquisas trazem um candidato fora da margem de erro, isso vem acompanhado de mais equívocos. É possível atestar que, para cada dez pesquisas, cinco apresentam erros em mais de um candidato analisado.

A partir dessa amostra, demonstrei como o método de coleta usado pelos institutos em pesquisas é falho. Com os problemas expostos, é necessário explicar os erros e apontar soluções que tornem as pesquisas um instrumento mais preciso de medição. 


\section{Problemas e formas de melhorar os resultados obtidos pelas pesquisas}

Como demonstrado, pesquisas não apresentam a precisão para serem consideradas confiáveis. Caso se leve em conta apenas o segundo turno, as pesquisas servem como referência para apontar quem deve ganhar. Quais são os motivos para os erros? Os principais argumentos utilizados pelos institutos são: (a) maior velocidade com que informações chegam e são acessadas pelos eleitores; (b) a demora para que os indivíduos decidam em quem votar; (c) o alto número de indecisos nos dias que antecedem o pleito. Além dessas justificativas, os institutos não evidenciam outras falhas internas que comprometeriam o seu produto como (d) a utilização da amostragem por cotas ao invés da amostragem aleatória, (e) a utilização da margem de erro e (f) o tempo médio de realização das entrevistas.

Mesmo que o primeiro argumento citado pelos institutos - de que as pessoas acessam mais informação sobre os candidatos em menos tempo - esteja correto, não é possível atestar com exatidão se isso ocorre. Isso poderia ser feito com um estudo de séries históricas. Seria possível constatar se há relação entre a quantidade de informações disponíveis na internet, a rapidez para acessá-las e a volatilidade do eleitor.

O segundo argumento, de que as pessoas hoje demoram mais para escolher seus candidatos, não pode ser comprovado. É uma hipótese válida, mas carece de estudos que provem sua correlação. A alternativa seria fazer uma comparação histórica, levando em conta a progressão da pesquisa sempre aliado ao resultado final das eleições. Assim, seria possível constatar mudanças de voto em cima da hora por meio de pesquisas feitas ao longo dos meses. O problema aqui não é a tomada de decisão em cima da hora, mas de que "o mapeamento de variáveis influenciadoras da decisão do voto é, sem dúvida, a grande tarefa para que as pesquisas sejam utilizadas no prognóstico e não apenas para a 'fotografia do momento"' (Berndt, 1989, p.85). 
A terceira justificativa usada pelos institutos é de que o alto número de indecisos prejudica a confiabilidade das pesquisas eleitorais. Podemos checar esse argumento com a tabela sobre a relação de indecisos por pesquisa analisada:

Tabela 1: Média do percentual de indecisos por pesquisas

\begin{tabular}{l|l|l|l}
\hline Indecisos & $\mathbf{1}^{\circ}$ turno & $\mathbf{2}^{\circ}$ turno & Geral \\
\hline $\mathbf{0 \%}$ a 5\% & $13(33,4)$ & $20(66,6 \%)$ & $33(100 \%)$ \\
\hline $\mathbf{5 , 0 1 \%}$ a 10\% & $25(89,2 \%)$ & $3(10,8 \%)$ & $28(100 \%)$ \\
\hline $\mathbf{1 0 , 0 1 \% ~ a ~ 1 5 \% ~}$ & $9(100 \%)$ & $0(0 \%)$ & $9(100 \%)$ \\
\hline $\mathbf{1 5 , 0 1 \%}$ a 20\% & $3(100 \%)$ & $0(0 \%)$ & $3(100 \%)$ \\
\hline Não informado & $1(25 \%)$ & $3(75 \%)$ & $4(100 \%)$ \\
\hline
\end{tabular}

Fonte: Elaboração do autor.

A maior parte das pesquisas apresenta de $0 \%$ a 10\% de indecisos: 61 das 77 analisadas. É nessa margem em que se concentra o maior número de acertos dos institutos: são 29 pesquisas com candidatos dentro da margem de erro, sendo 20 realizadas no segundo turno. Nenhuma dessas pesquisas teve mais de $10 \%$ de indecisos. É possível contestar a alegação de os indecisos serem o principal influenciador do resultado final. Isso porque, na maioria dos casos, o eleitorado já está inclinado em quem votar. Os dados também fornecem elementos para alegar que o fato de a pesquisa ter sido realizada no segundo turno influencia as medições. Pode-se apontar que a quantidade de indecisos é um fator de influência, mas não decisivo para o erro ou acerto dos institutos. Entretanto, parece haver relação entre o menor número de candidatos e o tempo de campanha.

As respostas para a quarta e para a quinta justificativas estão ligadas. A utilização da amostragem por cotas - definida pelo número de eleitores de cada região, cidade e zona eleitoral - é um equívoco. A amostragem probabilística apresenta maior precisão, mas possui maiores custos e é menos utilizada. Na amostragem por cotas, em cada lugar, é feita uma ordenação das maiores para as menores regiões, cidades e zonas eleitorais. 
Depois, são selecionadas em proporções semelhantes pessoas que representem uma amostra dos grupos etários, econômicos, raciais, sociais, culturais e políticos. Isso constitui uma "perfeita réplica" daquele universo. Mas os problemas começam quando se prova que não há indicação científica de que pessoas de um mesmo estrato votarão de forma semelhante. Assim, a amostragem por cotas "pode até ser representativa, mas, em relação àquelas variáveis populacionais identificáveis, não quanto à variável de interesse" (Ferraz, 1996, p.21-22). As amostras podem representar um segmento social, mas não indicam que tenham significado no processo eleitoral. Grupo de pessoas brancas com alto rendimento não constitui um grupo que pensa da mesma forma, embora possam ser apontadas semelhanças em seus modos de vida. Por isso, a amostra aleatória simples seria mais acertada para as pesquisas. A razão para isso é que

cada membro da população de interesse tem probabilidade igual de ser selecionado para constituir a amostra. Este tipo de amostra tem propriedades estatísticas importantes que nos permitem concluir com um certo grau de certeza o quão "perto" a amostra está de representar perfeitamente a população (Turgeon, 2009, p. 7).

Além disso, a amostragem por cotas não deveria incluir uma margem de erro. Isso não faria sentido do ponto de vista científico. Se os institutos insistem na utilização da amostragem probabilística por cotas, uma alternativa seria modificar a exigência da justiça e não apresentar mais margem de erro ou utilizar como método a amostra simples aleatória, que consiste em um método de entrevistas no qual se tem conhecimento de quem será entrevistado por meio de sorteio. Aqui, há um uso da margem de erro comprovado cientificamente, pois todos possuiriam chances iguais de serem escolhidos. Caberia ao entrevistador a obrigação de entrevistar aquele indivíduo. Esse tipo de amostra geraria mais custos e tempo.

A última alternativa levantada para a explicação dos erros é a de que quanto maior for o tempo utilizado para as entrevistas, maiores são os erros cometidos. Essa afirmação pode ser colocada à prova com um levantamento do tempo médio relacionado com a média de acertos e erros das pesquisas como na tabela abaixo: 
Tabela 2: Tempo médio em dias para realização das entrevistas comparado com os erros e acertos dentro da margem de erro proposto pelas medições

\begin{tabular}{l|l|l|l}
\hline $\begin{array}{l}\text { Tempo médio em dias } \\
\text { para a realização das } \\
\text { entrevistas para as pesquisas }\end{array}$ & Acertos & Erros & Total \\
\hline 2 dias & $4(28,6 \%)$ & $10(71,4 \%)$ & $14(100 \%)$ \\
\hline 3 dias & $14(51,9 \%)$ & $13(48,1 \%)$ & $27(100 \%)$ \\
\hline 4 dias & $4(28,6 \%)$ & $10(71,4 \%)$ & $14(100 \%)$ \\
\hline 5 dias & $1(20 \%)$ & $4(80 \%)$ & $5(100 \%)$ \\
\hline 6 dias & $5(31,2 \%)$ & $11(68,8 \%)$ & $16(100 \%)$ \\
\hline 8 dias & $0(0 \%)$ & $1(100 \%)$ & $1(100 \%)$ \\
\hline Total & $28(100 \%)$ & $49(100 \%)$ & $77(100 \%)$ \\
\hline Fonte: Elaboracão $d 0$ autor) & & &
\end{tabular}

Fonte: Elaboração do autor.

O balanço é inconclusivo para afirmar se há relação entre o tempo médio de realização das entrevistas e a precisão da pesquisa. Embora o maior número de acertos tenha sido das pesquisas terminadas em três dias, é necessário afirmar que nove dos 13 acertos são de pesquisas realizadas no segundo turno. Além disso, houve diferença entre os acertos das pesquisas que fizeram as entrevistas em dois e as que realizaram o procedimento em seis dias. Considerando a quantidade de acertos das pesquisas, o tempo médio que trouxe a maior quantidade de acertos foi em pesquisas realizadas em três dias. Medições feitas nesse tempo foram as únicas que apresentaram acerto superior a 50\%. Por sua vez, pesquisas de dois e quatro dias apresentaram resultados idênticos. Foram 14 pesquisas realizadas em cada um desses dias e em cada caso houve erro em quase três quartos da amostra. Até as pesquisas realizadas em seis dias apresentaram dados melhores aos encontrados nas pesquisas feitas em dois ou quatro dias. A amostragem não permite chegar a nenhuma conclusão que permita apontar se há correlação entre o tempo médio gasto para fazer as pesquisas e o índice de acerto. Esta hipótese deve ser aprofundada com um escopo maior de pesquisas. Só assim seria possível dizer se há ou não relação entre os fatos. 


\section{Fatores externos que podem atrapalhar as medições das pesquisas}

Existem outras explicações para os erros cometidos pelos institutos em pesquisas como o "efeito bandwagon", que é a tendência de o eleitor votar no candidato que surge como provável vencedor. Outra dificuldade constatada (Lavrakas e Tragott, 2000) é a de mensurar o "efeito underdog", tendência de o eleitor sempre apoiar o candidato mais fraco. Outro ponto a considerar é a dificuldade que as pesquisas empíricas possuem em medir de forma isolada o impacto das pesquisas sobre o eleitor (Nunes, Olsén e Straubhaar, 1993). Podemos usar o exemplo do caso citado por Nunes, Olsén e Straubhaar (1993) de uma pesquisa realizada no Brasil, em 1989, na qual se verificou que $15,7 \%$ dos eleitores usaram informações obtidas nas pesquisas na hora de decidir seu voto. Uma parte desses eleitores, representando 7,2\% da amostra, indicaram comportamento bandwagon, enquanto 8,5\% mostraram tendência underdog.

Como explica Mendes (1991), entre os eleitores que consideram importantes as pesquisas como fonte de informação, uma parte usa as pesquisas para potencializar, por meio de um cálculo racional, sua preferência no jogo eleitoral. Mendes sustenta que as pesquisas divulgadas pela mídia funcionam como instrumento de democratização de informações. Com elas, o eleitor agiria de maneira racional, deixando de escolher um candidato com quem tem mais afinidade, mas sem chances de vitória, para escolher uma segunda opção. Nesse caso, a escolha racional corresponderia ao comportamento de uma parte do eleitorado. Isso seria correto para o eleitor mais politicamente envolvido e sofisticado. É o fenômeno do "voto útil" que se constitui como uma decisão adotada por parte dos eleitores. Independentemente de as escolhas serem orientadas por elementos de natureza distinta (como sensibilidade, juízo de gosto, emoções, imagens ou intuições) ou estratégias racionais, é aceitável o argumento de que as pesquisas geram dados importantes para o ambiente de informações na tomada de decisão do eleitor (Meyer, 1989). 
Outra influência indireta que as pesquisas recebem é referente às fontes de financiamento de campanhas e a mobilização das militâncias. Candidatos melhor posicionados nas pesquisas tem maior apoio político. Isso faz com que haja melhora nas doações, o que gera espaço na mídia e maior mobilização das bases partidárias. Do outro lado, quem não consegue bons índices nas pesquisas perdem espaço nos espaços de disputa, o que leva a desmobilização política (Silveira, 1991; Almeida, 2002).

Além desses fatores, existem outras possibilidades de erros nas pesquisas. Em menor proporção, os erros ocorrem devido ao desenho do plano amostral. É necessário mencionar problemas epistemológicos e os efeitos de quantificação de opiniões. Opiniões correspondem ao resultado de complexos processos que envolvem percepções do mundo político e social, vínculos socialmente estabelecidos, a cultura política de setores diferentes do eleitorado e a identidade construída politicamente. Logo, a mesma opinião de um assunto será agrupada por diferentes processos. Como mostra Silveira (1998), estudos atestam que eleitores revelam fraca inter-relação lógica entre as ideias políticas. Parte dessas ideias são fundadas em relações intersubjetivas, em experiências práticas, em relações afetivas ou associadas a relações de interesse. Isso mostra que opiniões são mantidas como convicção por indivíduos, enquanto outras são apenas impressões. Essas últimas são mais propensas às mudanças. Intenções e opiniões que têm a mesma expressão são produtos do processo de decisão tomados de forma diferentes. O problema, segundo Silveira (1998), é que esses eleitores são considerados de forma uniforme na pesquisa, como se possuíssem opiniões equivalentes. O que está longe de ser verdade.

Foddy (1996) enfatiza que o problema decorre da má elaboração das perguntas no instrumento de pesquisa. Segundo o autor, as mudanças nos termos de uma pesquisa alteram os resultados obtidos. Ele usa o exemplo de uma pesquisa inglesa que, ao mudar a ênfase das palavras "ficar" ou "sair" do Mercado Comum Europeu, o resultado da pesquisa era alterado. Quando a consulta era feita com "deveria sair", o resultado apontava empate técnico. Se a formulação era "deve ficar", as respostas mostravam $18 \%$ de diferença para ficar. Além das diferenças que surgem dos termos, ainda existem problemas na construção do instrumento. É comum encontrar falhas na interpretação das perguntas formuladas aos entrevistados. Além disso, a ordem das perguntas altera o 
conteúdo das respostas e a ordem das alternativas pré-codificadas como respostas possíveis a uma pergunta também afeta a manifestação do entrevistado.

Uma avaliação mais confiável das tendências eleitorais deve considerar não só a intenção de voto declarada, mas também outros elementos como a imagem dos candidatos, o grau de rejeição, o grau de "cristalização" do voto, a tendência de voto dos indecisos e o impacto de questões relevantes para a disputa eleitoral (Silveira, 2002, p. 374).

Merecem ser registrados problemas que ocorrem na interpretação incorreta pela mídia dos resultados das pesquisas. A divulgação dos resultados a jornalistas que não conhecem aspectos técnicos faz com que haja incompreensão das pesquisas. Também existe o interesse do jornal em produzir manchetes com apelo midiático. Nesses casos, é comum, como mostra Almeida (2002), que jornalistas ressaltem pequenas mudanças nos índices como se significassem grandes mudanças.

Também é necessário fazer apontamentos estatísticos. As pesquisas eleitorais fazem levantamento de uma amostra aleatória de eleitores e de estimativas do nível populacional, tomando uma média ponderada das respostas, em que os pesos são projetados para corrigir diferenças entre a amostra e a população. Este quadro de análise produz uma estimativa de erro na previsão devido à variância da amostra que representa os pesos da pesquisa (Lohr, 2009). Na prática, os pesos de uma amostra são iguais e a maioria das organizações de pesquisa relatam $95 \%$ de margens de erro, idênticas às da amostragem aleatória simples sem que sejam incorporadas ao efeito dos pesos. Essa abordagem para quantificar o erro das pesquisas é conhecida pelas discrepâncias entre os resultados das eleições e das pesquisas, podendo parcialmente ser atribuídos à variância da amostra (Ansolabehere e Berlin, 1993). Como mostra a literatura sobre o erro total de pesquisas (Biemer, 2010; Groves e Lyberg, 2010), há quatro tipos adicionais de equívocos que não se refletem nas margens de erro relatadas: (1) frame; (2) não resposta; (3) medida e (4) especificação. 
$\mathrm{O}$ erro de frame acontece quando há incompatibilidade entre a moldura da amostragem e a população-alvo. Por exemplo, para pesquisas por telefone, as pessoas que não possuem telefone não serão incluídas na amostra. $\mathrm{O}$ quadro de amostragem é importante para as pesquisas por incluir pessoas que não estão na eleição ou que não conhecem o cenário político. Isso é corrigido com perguntas mais específicas. A segunda forma, o erro de não-resposta, é quando os valores em falta estão relacionados de forma sistemática com a resposta. No caso, de apoiantes do candidato no último lugar serem menos propensos a responder às pesquisas do que os eleitores que são bem posicionados (Gelman, Goel, Rivers e Rothschild, 2016). Essa preocupação é crescente já que a taxa de não resposta chega até 90\% (Pew Research Center, 2016). Já o erro de medição aparece quando o instrumento de levantamento reflete a resposta, como o efeito de ordem (McFarland, 1981) ou a formulação de perguntas (Smith, 1987). Por fim, o erro de especificação acontece quando a interpretação de uma pergunta feita decorre do que o entrevistador deseja transmitir (como em questões em que há barreira linguística). Além desses erros, há uma complicação adicional: a mudança de atitude dos eleitores. O motivo é que as pesquisas avaliam o que os respondentes farão no dia da eleição, mas elas só podem realmente medir as crenças atuais desses eleitores.

A volatilidade eleitoral no Brasil também pode ser apresentada como um dado para justificar os erros em pesquisas. Mas, como Bohn e Paiva (2009) demonstram, a volatilidade apresenta um declínio. Em estudo longitudinal, elas analisaram as eleições de 1982 até 2008 e concluíram que nas eleições legislativas e no poder executivo, os dados mostram que há redução da volatilidade eleitoral dos eleitores.

Os dados (...) permitem afirmar que as taxas de volatilidade eleitoral apresentam um padrão geral de declínio. A tendência é geral em dois sentidos. Em primeiro lugar, a oscilação no apoio agregado dos brasileiros às ofertas eleitorais tem se reduzido no decorrer do tempo desde 1982 (ou 1989, no caso das eleições presidenciais) para todos os tipos de pleito, com exceção das eleições senatoriais. Em segundo lugar, boa parte das unidades da federação, reproduz, no plano estadual, o padrão observado no âmbito federal (Bohn e Paiva, 2009, p.203). 


\section{Considerações finais}

Pesquisas estão no imaginário popular como uma eficaz ferramenta para medir a intenção de voto. Essas medições representam o olhar imparcial responsável por dar voz ao público e mostrar suas preferências. Tudo isso por meio de percentuais que atestam a competência dos métodos cientificamente desenvolvidos ao longo do século passado. Diante disso, chama atenção os poucos estudos que buscam destrinchar até que ponto os institutos entregam os índices de confiança que prometem.

As pesquisas precisam aprimorar suas técnicas de medição para alcançar a confiabilidade que propagam. Se olharmos as avaliações dos institutos pelos candidatos individualmente e para os percentuais atribuídos pelas pesquisas, os números de confiabilidade atingem $69,2 \%$. Isso representa que, a cada dez candidatos pesquisados, os institutos acertaram dentro das margens de erro uma média próxima a sete nomes. Agora, se olharmos as pesquisas que antecederam as eleições do primeiro e do segundo turno para governador em 2014, apenas 37,6\% estavam com todos candidatos na margem de erro alegada à justiça. Ou seja, menos de quatro acertos para cada dez pesquisas divulgadas e distante do padrão de $95 \%$ de confiabilidade. Outro dado que reforça que as medições precisam melhorar está na seguinte informação: em apenas 15,5\% das previsões houve troca de posições.

Com este estudo, foram apresentados dados que reforçam a tese de que as pesquisas precisam melhorar a sua coleta de dados para entregar o que prometem. Além disso, há elementos externos às pesquisas que prejudicam qualquer medição. É preciso levar em conta o cálculo racional que surge dos eleitores ao analisar o resultado das pesquisas, o incentivo ou desmotivação da militância após a divulgação do resultado das medições, assim como acréscimos ou não de recursos de doação para candidatos mais bem posicionados. A volatilidade do eleitor também é afetada por informações que surgem na internet. Esses elementos externos, somados aos internos, reforçam a tese de que as pesquisas ainda não alcançam a precisão que atestam. 
Além disso, este estudo demonstrou que as pesquisas conseguem, no máximo, apontar qual será o candidato vencedor em medições realizadas nas vésperas das votações do segundo turno. E isso é pouco levando em conta a atenção midiática que recebem e os custos envolvidos na empreitada. Esse estudo é um esforço para demonstrar que os institutos de pesquisas precisam refinar seus métodos para descobrir em quem os eleitores irão votar. Essa melhora precisa ser imediata. Atualmente, as pesquisas apontam tendências, principalmente, no segundo turno das eleições. Mas, no primeiro turno, em que há muitos candidatos em disputa, os erros são maiores. É necessário refinar o método de coleta. Somente assim, as medições se tornarão uma ferramenta útil para demonstrar uma realidade de um momento e para se democratizar a informação eleitoral.

Os dados obtidos nesse estudo são insuficientes para que suas conclusões sejam generalizáveis. Outras pesquisas são necessárias. É preciso entender se há relação e qual a relação entre a melhora tecnológica e a dificuldade de medir a opinião pública em questões eleitorais. São necessários estudos com séries históricas para constatar fenômenos mais recentes, como se há uma demora acentuada das pessoas ao escolherem seus candidatos. Também é preciso mudar a percepção do público em geral sobre o papel que a pesquisa possui. Ela é vendida como a "fotografia do momento", trazendo um indicativo, pela margem de erro, de onde os candidatos irão estar quando os votos forem contabilizados. Para que isso se transforme em realidade, a precisão precisa melhorar. Entre as sugestões para tornar a pesquisa mais exata está a utilização das entrevistas por meio de amostragem simples ao invés de amostragem por cotas e o fim da utilização da margem de erro.

Se a utilização da pesquisa é parte importante do processo eleitoral, ela precisa ser entendida e quantificada. Isso deve ser feito por meio de uma coleta de dados mais ampla - que reúna várias eleições - e que possibilite olhares e interpretações sobre o assunto. Só assim teremos um olhar mais preciso de qual é o papel exercido pelas pesquisas eleitorais no Brasil. 


\begin{abstract}
Notas
${ }^{1}$ Agradeço as sugestões recebidas dos pareceristas, que contribuíram positivamente para a versão final deste artigo.

2 Nos links do UOL citados nas referências podem ser consultadas as seguintes pesquisas: $1^{\circ}$ e $2^{\circ}$ turno: AC, AP, AM, CE, DF, GO, MS, PA, PB, RJ, RN, RS, RO e RR. Do $1^{\circ}$ turno, foram consultadas as pesquisas de AL, BA, ES, MA, MT, MG, PR, PE, PI, SC, SP e TO.
\end{abstract}

\title{
Referências
}

ALMEIDA, Alberto Carlos. Como são feitas as pesquisas eleitorais e de opinião. Rio de Janeiro, Editora FGV, 2002.

ANSOLABEHERE, Stephen; BELIN, Thomas R. Poll faulting. Chance, 1993.

AMARAL, Roberto. Imprensa e controle da opinião pública (informação e representação popular no mundo globalizado). Comunicação \& Política, v. 7, n. 3, p. 128-158, Rio de Janeiro, Cebela, 2000.

ARENDT, Hannah. Entre o Passado e o Futuro. Tradução Mauro W. Barbosa de Almeida. São Paulo: Perspectiva, 1972.

BERNDT, Alexandre. Erros nas pesquisas eleitorais. Revista de Administração. São Paulo, 1989.

BIEMER, Paul P. Total survey error: Design, implementation, and evaluation. Public Opinion Quarterly, 74: p.817-848, 2010.

BISHIN, Benjamin. Tyranny of the Minority: The Subconstituency Politics Theory of Representation. Philadelphia: Temple University Press, 2009.

BOURDIEU, Pierre. "A opinião pública não existe”, Thiollent, Michel. Crítica metodológica, investigação social e enquete operária. São Paulo: Polis, p. 137-151, 1982.

CARVALHO, Jessé F.; FERRAZ, Cristiano. A Falsidade das Margens de Erro de Pesquisas Eleitorais Baseadas em Amostragem por Quotas. Seminário "A Estatística na Pesquisa Eleitoral", São Paulo, 2006.

CHAMPAGNE, Patrick. Formar a opinião - o novo jogo político. Petrópolis: Vozes, 1998.

. "Fazendo o povo falar: sobre os usos sociais das pesquisas de opinião e as reações a elas" em Wacquant, Loic (org.). O mistério do ministério - Pierre Bourdieu e a política democrática. Rio de Janeiro: Revan, 2005.

DONSBACH, Wolfgang; TRAUGOTT, Michael W. "Introduction" em Donsbach, Wolfgang e Traugott, Michael W. (org). The Sage handbook of public opinion research. Londres: Sage Publications, p. 1-6, 2008.

FODDY, William. Como perguntar: teoria e prática da construção de perguntas em entrevistas e questionários. Oeiras: Celta Editora, 1996. 
GELMAN, Andrew; GOEL, Sharad; RIVERS, Douglas; ROTHSCHILD, David. The mythical swing voter. Quarterly Journal of Political Science, 11: p. 103-130, 2016.

GOMES, Wilson. Transformações da política na era da comunicação de massa. São Paulo: Paulus Editora, 2004.

GROVES, Robert M.; LYBERG, Lars. Total survey error: Past, present, and future. Public Opinion Quarterly, 74: p. 849-879, 2010.

HABERMAS, Jürgen. Mudança estrutural da esfera pública. Rio de Janeiro: Tempo Brasileiro, 1984.

HERBST, Susan. Numbered voices - how opinion polling has shaped American politics. Chicago: The University of Chicago Press, 1993.

LAVRAKAS, P.J.; TRAUGOTT, M. W. Election polls, the news media and democracy. New York: Chatham House, 2000.

LIPPMANN, Walter. Opinião pública. Petrópolis: Vozes, 2008.

LOCKE, John. Segundo tratado sobre o governo. São Paulo: Abril Cultural, 1978.

LOHR, Sharon. Sampling: Design and Analysis. Nelson Education, 2009.

MANIN, Bernard. As metamorfoses do governo representativo. Revista Brasileira de Ciências Sociais. ANPOCS, n² 29, 1995.

McFARLAND, Sam G. Effects of question order on survey responses. Public Opinion Quarterly, $n^{\circ}$ 45: p. 208-215, 1981.

MEIRA, João Francisco. "Metodologias, confiabilidade, impacto e utilidade: as várias faces da pesquisa eleitoral no Brasil" em Revista Em Debate: Opinião Pública e Conjuntura Política. v. 5, Ano 2, slp. Belo Horizonte, 2010.

MENDES, Antônio M. T. O papel das pesquisas eleitorais. São Paulo: Novos Estudos Cebrap, ํㅡㄴ 29, 1991.

MEYER, Philip. Precision journalism and 1988 US elections. International Journal of Public Research, v. 1, ํo 3, 1989.

NOELLE-NEUMANN, Elisabeth. The spiral of silence: public opinion - our social skin. Chicago: The University of Chicago Press, 1993.

NUNES, Márcia Cavallari; OLSÉN, Örjan; STRAUBHAAR, Joseph. O uso de pesquisas eleitorais em decisões de voto: as eleições brasileiras de 1989. Opinião pública, v. 1, ㄲo 2, 1993.

OLIVEIRA, Adriano. "Pesquisas eleitorais e disputa presidencial de 2010" em Revista Em Debate: Opinião Pública e Conjuntura Política. v. 5, słp. Belo Horizonte, 2010.

PAIVA, Denise; BOHN, Simone. A volatilidade eleitoral nos estados. Revista de Sociologia e Política, Curitiba, v. 17, n 33, jun, 2009, p. 187-208, 2009.

SILVEIRA, Flavio E. A decisão do voto no Brasil. Porto Alegre: Edipucrs. Pesquisas, enquetes e estudos eleitorais. Civitas, v.2, no 2, dez, p. 351-384. Porto Alegre, 2002. 
A decisão do voto no Brasil. Porto Alegre: Edipucrs, 1991. 1998.

Pesquisas eleitorais e voto no Brasil. Revista de Ciências Humanas. Porto Alegre, no 12,

SMITH, Tom W. That which we call welfare by any other name would smell sweeter: An analysis of the impact of question wording on response patterns. Public Opinion Quarterly, $n^{\circ} 51$ : p. $75-$ 83, 1987.

TOCQUVILLE, Alexis. A democracia nas Américas: leis e costumes de certas leis e certos costumes políticos que foram naturalmente sugeridos aos americanos por seu estado social democrático. São Paulo: Editora Itatiaia, 1998.

TURGEON, Mathieu. "O uso de pesquisas de opinião pública nas democracias modernas" em Revista Em Debate: Opinião Pública e Conjuntura Política. Volume 3, Ano 1, slp. Belo Horizonte, 2009.

TRIBUNAL REGIONAL ELEITORAL DO SERGIPE. Manual sobre pesquisa eleitoral. Aracaju, 2014.

\section{Sites consultados}

AC24HORAS. Sebastião Viana ganha nas pesquisas da Vox Populi e lbope, mas perde na Delta. O Alto Acre, 2014. Link: http://migre.me/wKz8B. Consulta: 28/03/2016.

AMAZONAS ATUAL. Pesquisa DMP/Tiradentes aponta segundo turno entre Braga e Melo. Amazonas Atual, 2014. Link: http://migre.me/wKz8m. Consulta: 28/03/2016.

BRITES, Elizio. Levantamento Fiems-Ibrape aponta chances de Delcídio vencer no $1^{\circ}$ turno. O Estado, 2014. Link: http://migre.me/wKz7h. Consulta: 28/03/2016.

CARVALHO, Fábio. DATAMAX: W.Dias 49\%, Zé Filho 38\% e Mão Santa com 6\%. 180, 2014. Link: http://migre.me/wKz6w. Consulta: 28/03/2016.

DANTAS, Diógenes. Robinson já vence Henrique no $1^{\circ}$ e $2^{\circ}$ turnos, aponta Seta/Nominuto. No Minuto.com, 2014. Link: http://migre.me/wKz5Y. Consulta: 28/03/2016.

DA REDAÇÃO. A seis dias das eleições, Waldez tem 40,39\% para o governo e Gilvam com 35,18\% para o Senado. Jornal do Dia, 2014. Link: http://migre.me/wKz4n. Consulta: 28/03/2016.

DA REDAÇÃO. Ipespe, votos válidos: Ricardo tem 52\% e Cássio, 48\%, na Paraíba. G1, 2014 Link: http://migre.me/wKz4b. Consulta: 28/03/2016.

DA REDAÇÃO. Dataform: Jackson deve ser reeleito com 55\% dos votos válidos. Sergipe 247 , 2014. Link: http://migre.me/wKz3D. Consulta: 28/03/2016.

DA REDAÇÃO. Pesquisa aponta Suely na frente da disputa ao governo de Roraima. Folha BV, 2014. Link: http://migre.me/wKz3n. Consulta: 28/03/2016.

DA REDAÇÃO. Pesquisa do Instituto DIÁRIO: Melo tem 54,4\% e Braga, 45,6\%. D24am, 2014. Link: http://migre.me/wKz3d. Consulta: 28/03/2016. 
DA REDAÇÃO. Pesquisa para o segundo turno das eleições em Rondônia. Jornal Rondoniense, 2014. Link: http://migre.me/wKz2L. Consulta: dia 28/03/2016.

DA REDAÇÃO. Souza Lopes/Correio aponta Cássio com 44,9\%, Ricardo com 38,1\% e Vital com 3,8\%. Portal Correio, 2014. Link: http://migre.me/wKz2r. Consulta: 28/03/2016.

FIORI, Sônia. Taques é o favorito com 41\% dos votos. Gazeta Digital, 2014. Link: http://migre.me/wKz21. Consulta: 28/03/2016.

FREIRE, Roland. Pesquisa TNH1/IPESPE: Renan Filho 36\%, Benedito de Lira 27\% e Júlio Cezar 2\%. THN1, 2014. Link: http://migre.me/wKz16. Consulta: 28/03/2016.

O LIBERAL. Jatene está 7,4\% pontos à frente de Helder, diz pesquisa. O Liberal News, 2014. Link: http://migre.me/wKz02. Consulta: 28/03/2016.

REDAÇÃO. Instituto Econométrica divulga última pesquisa antes da eleição que ocorre amanhã para governador. Jornal O Imparcial, 2014. Link: http://migre.me/wKyXZ. Consulta: 28/03/2016.

REDAÇÃO. Paulo Souto e Rui Costa empatam em pesquisa Babesp. Pimeta.blog.br, 2014. Link: http://migre.me/wKyX5. Consulta: 28/03/2016.

REDAÇÃO. Simão Jatente tem 44,7\%, Helder Barbalho 37,8\%. O Carneiro, 2014. Link: http://migre.me/wKyWE. Consulta: 28/03/2016.

REDAÇÃO FOLHA VITÓRIA. Hartung mantém favoritismo e Casagrande diminui diferença às vésperas das Eleições, aponta pesquisa FlexConsult. Folha Vitória. Link: http://migre.me/wKyW8. Consulta: 28/03/2016.

TAVARES, Altair. Serpes/O Popular: Marconi tem 51,13\% dos votos válidos; segundo turno indefinido. Diário de Goiás. Link: http://migre.me/wKyVR. Consulta: 28/03/2016.

REDAÇÃO. Pesquisa aponta vitória de Colombo no primeiro turno e empate técnico para Senado e presidência. Notícias do Dias, 2014. Link: http://migre.me/wKyVI. Consulta: 28/03/2016.

REDAÇÃO. Serpes/O Popular: Marconi tem 58,4\% dos votos válidos, Iris 41,5\%. Diário de Goiás, 2014. Link: http://migre.me/wKyVE. Consulta: 28/03/2016.

SANTOS, Marcos. Pesquisa SBT aponta eleição de Reinaldo com $57,53 \%$ dos votos. 0 Progresso, 2014. Link: http://migre.me/wKyUQ. Consulta: 28/03/2016.

UOL. Pesquisas eleitorais. Link: https://eleicoes.uol.com.br/2014/pesquisas-eleitorais. Consulta: 05/06/2017.

Pew Research Center (2016). Our survey methodology in detail. Link: http://migre.me/wKyUg, 2016. Consulta: 24/05/2017.

VAZ, Roberto. Sebastião Viana está a menos de 5\% de uma vitória no $1^{\circ}$ turno, aponta pesquisa Delta, AC24horas.com, 2014. Link: http://migre.me/wKyU1. Consulta: 28/03/2016. 


\section{O autor}

João Kamradt é doutorando em Sociologia Política pela UFSC. Mestre no mesmo programa e curso. Formado em Comunicação Social com ênfase em Jornalismo pelo lelusc. Estuda mídia, representação política e eleições. joaokamradt@gmail.com 